\title{
NopU
}

ISSN: $2318-1966$

v. 4, n. 5

jan - jul 2016

Artigos

\section{FORMAS DE ORGANIZAÇÃO DA DEMANDA DE FIRMAS DE TI NO MERCADO DE TRABALHO}

Lucas Rodrigues Azambuja Pós-Doutorado em Sociologia pela Universidade Federal do Rio Grande do Sul (2015). Doutor em Sociologia pela Universidade de São Paulo (2013). Mestre em Sociologia pela Universidade Federal do Rio Grande do Sul (2007). Professor Adjunto I no IBMEC-MG. Pesquisador associado ao Grupo de Pesquisa Sociedade, Economia e Trabalho (UFRGS).

\begin{abstract}
RESUMO
Este artigo propõe compreender o comportamento das firmas no mercado de trabalho, apontando para a relação entre características organizacionais da empresa e a maneira com que a mesma organização o conjunto de relações sociotécnicas para demandar no mercado de trabalho. Foi analisada a inter-relação entre características das redes sociotécnicas e as características organizacionais da chamada nova economia, com o objetivo de compreender o processo de construção social sobre o qual assenta a ida das empresas como demandantes no mercado de trabalho. Procedeu-se à realização de quatro estudos de casos em empresas de tecnologias da informação, localizadas em Porto Alegre (RS) e região metropolitana. Com base na análise dos dados coletados, constatou-se que quanto mais uma firma apresenta características organizacionais típicas da nova economia, maior o número de agentes integrados em sua rede sociotécnica e mais intensas serão as relações entre eles.
\end{abstract}

Palavras-Chave: Nova Economia; Redes Sociotécnicas; Cálculo Econômico; Mercado de Trabalho; Firmas.

\section{ORGANIZATIONAL FORMS OF DEMAND IN TI COMPANIES IN THE LABOUR MARKET}

\begin{abstract}
This paper proposes to understend the behavior of companies in the labour market, looking fot the relation between company organizational characteristics and the way that this organization makes its set of socio-technical relationships in the labour market. It was made the inter-relation between socio-technical networks relationships with the organizational relationship of the new economy, with the aim to understand the process of social construction that is based the companies steps as plaintiffs in the labour market. It was made by four cases researches in information technology companies, based in Porto Alegre (RS) and its metropolitan region. Based on the analysis of its colected datas, it was found that how much a company presents typical organizational characteristics of the new economy, the bigger is the number of integrated agents in your sociotechnical networkd and more intense are the relationships between them.
\end{abstract}

Keywords: New economy; Socio-technical networks; Economic Calculation; Labour market; Companies. 
NORUS - v4, n.5, jan - jul 2016.

\section{INTRODUÇÃO}

A chamada Nova Sociologia Econômica (FLIGSTEIN e DAUTER, 2007; PORTES, 2010; SMELSER e SWEDBERG, 2005; STEINER, 2006) tem demonstrado que o encontro e transações nos mercados não são decorrências automáticas ou naturais, isto é, as transações mercantis se assentam em processos de construção social, nos quais incidem a influência de condicionantes extra-econômicos, por exemplo, as redes de relações sociais, as instituições, normas e valores culturais, entre outros. A partir dessa perspectiva forma-se outra imagem dos agentes e sua ação dentro dos mercados, uma imagem que se afasta da figura tradicional de agentes econômicos que adentram ao mercado com preferências formadas e que respondem exclusivamente aos sinais emitidos pelo sistema de preços. Assim sendo, o agente econômico, que emerge da perspectiva da Nova Sociologia Econômica (NSE), está inserido no mercado de maneira "aparelhada", ou seja, enraizado em condicionantes de natureza econômica e extra-econômica. As suas capacidades de ação (nível de incerteza e informação, modalidades de racionalidade, juízos e escolhas) e os resultados que obtém nas transações de mercado, tornam-se compreensíveis somente levando em consideração esses condicionantes.

Este artigo se insere na abordagem da NSE ao propor compreender o comportamento das firmas como demandantes no mercado de trabalho, através do conjunto de relações sociotécnicas que estruturam as condições para exercerem sua capacidade de cálculo. O que se evidencia neste estudo é que como demandantes, as firmas não agem de maneira automática, somente calculando a maximização do seu interesse a partir das relações entre quantidades e preços; mas o fazem exercendo sua capacidade de cálculo em função das condições de possibilidade engendradas pelas redes sociotécnicas nas quais as firmas estão enraizadas.

Com base na perspectiva de análise de redes sociotécnicas da NSE, mais comumente conhecida como "teoria do ator-rede" (CALLON, 1998, 2004; LATOUR, 2006; LAW, 1999), visamos contribuir para o entendimento de que a ida da firma como demandante no mercado de trabalho consiste em um fenômeno socialmente enraizado.

Cabe destacar que as redes sociotécnicas não são formadas aleatoriamente. Neste estudo, evidenciamos que algumas características das redes sociotécnicas dependem de aspectos organizacionais das empresas que, por sua vez, estão relacionadas ao contexto social e econômico mais amplo. Assim sendo, cabe deixar claro que neste artigo não pretendemos fazer uma análise das relações e dispositivos sociotécnicos, mas unicamente examinar a conexão entre aspectos organizacionais da nova economia e duas características morfológicas das redes sociotécnicas, a saber, quantidade de agentes humanos e não-humanos e de interações entre os mesmos. 


\section{Formas de organização da demanda de firmas de TI no mercado de trabalho}

Nesse sentido, é cada vez mais consensual entre autores das Ciências Sociais, o argumento de estarmos presenciando o início de uma nova etapa do desenvolvimento histórico do capitalismo. Argumenta-se em favor do surgimento de um novo paradigma de produção e desenvolvimento, isto é, de uma nova economia. Essa última recebeu diferentes nominações, por exemplo, sociedade pósindustrial (BELL, 1973), capitalismo informacional (CASTELLS, 2007), pós-fordismo (HARVEY, 1996); pós-modernidade (JAMESON, 1985); economia do conhecimento (POWELL; SNELLMAN, 2004) e sociedade da informação (MASUDA, 1982). Cada qual dessas perspectivas tem registrado, de uma maneira ou de outra, a perda da centralidade no desenvolvimento econômico da grande indústria voltada para o consumo de massa; a revolução tecnológica em torno do surgimento e difusão das tecnologias da informação; alterações nos modelos de gestão das empresas, afastando-se do chamado paradigma taylorista-fordista; transformações nas condições e nas relações de trabalho e de emprego, marcadas pela tendência à flexibilização ou à precarização, dependendo da corrente de interpretação que se considere.

Como não podia ser diferente, o surgimento da nova economia também veio acompanhado de transformações no interior das empresas. A maior parte da literatura que se debruça sobre os processos recentes de mudança econômica tem destacado o rompimento com o modelo de organização da economia centrado na lógica taylorista-fordista da indústria de produção de massa, com suas sólidas hierarquias organizacionais, elevada centralização, alto grau de especialização das tarefas no processo produtivo e com suas rígidas relações de trabalho e de emprego. Conquanto preocupada em não recair no determinismo tecnológico, essa literatura não resiste em atribuir às tecnologias da informação um protagonismo no encaminhamento e lógica dessas transformações econômicas recentes, que estariam rompendo com o paradigma anterior.

Dentre outros, o trabalho de Manuel Castells (2007) se destaca ao defender que, no que ele chama de "capitalismo informacional", o desenvolvimento e funcionamento da economia passam a estar centrados na capacidade de geração de novas tecnologias que atuem na produção, processamento e circulação do conhecimento e informação; diferente do capitalismo industrial movido pelos investimentos em fontes de energias e pelo incremento no uso de capital físico no processo produtivo. Por isso mesmo, ressalta Castells, se antes o conhecimento só tinha valor por sua aplicação em tecnologias que maximizassem a produtividade, no capitalismo informacional, ele importa por sua capacidade de desenvolver tecnologias propulsoras da produção e processamento da (própria) informação e conhecimento, daí a centralidade e protagonismo das tecnologias da informação. 
NORUS - v4, n.5, jan - jul 2016.

Todavia, essa perspectiva não confere atenção principal às dinâmicas internas dos mercados como, por exemplo, as formas de organização do cálculo econômico. Por isso mesmo, recorre-se novamente ao repertório analítico de Michel Callon, em seu esforço por oferecer uma perspectiva de análise sobre a nova economia centrada na compreensão do funcionamento do cálculo econômico (CALLON, 2007; CALLON; MÉADEL; RABEHARISOA, 2002). Através da noção de “economia de qualidades", Callon define a nova economia em termos de um contexto no qual a organização e o funcionamento dos mercados dependem de relações sociotécnicas crescentemente complexas e que reúnem maior variabilidade de agentes para interagirem no processo de (re)qualificação de produtos, ou seja, no processo de cálculo econômico dos bens e serviços ofertados. Assim pensando, atribui um caráter central e peculiar às tecnologias da informação na economia de qualidades, uma vez que sua função seria justamente a de coordenar as relações sociotécnicas requeridas pelos processos de (re)qualificação de produtos.

A perspectiva de Callon sobre a nova economia é, portanto, centrada na compreensão do funcionamento dos mercados, destacando a crescente complexidade de relações sociotécnicas nos processos de cálculo dos bens e serviços neles ofertados. Desse modo, Callon coloca no centro da sua concepção sobre a nova economia - ou sobre a economia de qualidades, como prefere - o processo de cálculo, e nele destaca o papel das tecnologias da informação.

Ora, este é exatamente o ponto que se propõe investigar neste artigo e a pista analítica aberta por Callon será central nesse sentido. Isso porque esta pesquisa empreende o esforço de investigar como os mecanismos de cálculo se manifestam igualmente quando empresas chegam ao mercado de trabalho na condição de compradoras do insumo que lhes será fundamental, o trabalho. Em outros termos, se para as firmas como ofertantes é fundamental saberem lidar com relações sociotécnicas crescentemente complexas para calcular o valor do seu produto; compreende-se que os processos de cálculo, assentados em redes sociotécnicas, são igualmente importantes quando as empresas produtoras daquelas tecnologias vitais nas economias de qualidade lançam-se em busca dos trabalhadores que precisam contratar para a produção de tais produtos, de tão elevado valor estratégico. Portanto, o estudo que aqui se apresenta encontra sua razão de ser analítica e sua novidade interpretativa no esforço por trazer para o centro da análise o cálculo econômico por firmas de tecnologia da informação quando estas comparecem no mercado de trabalho, visando indicar que a mesma tendência de aumento da complexidade nas redes sociotécnicas das empresas, que Callon identifica nos mercados de produtos da "nova economia", também pode ser vislumbrada quando a firma comparece no mercado de trabalho. 


\section{Formas de organização da demanda de firmas de TI no mercado de trabalho}

Tendo em vista esse objetivo, procedeu-se à realização de quatro estudos de casos em empresas de diferentes segmentos de atividade econômica das tecnologias da informação (TI). Elegeram-se empresas de TI porque, mesmo preocupada em não recair no determinismo tecnológico, a literatura sobre a nova economia não resiste em atribuir às tecnologias da informação um protagonismo no encaminhamento e lógica das transformações econômicas e sociais recentes.

O artigo está, então, dividido em cinco partes: 1) exposição do marco teórico sobre a noção de cálculo econômico e da sua relação com a de redes socioténcias; 2) literatura sobre nova economia e suas características organizacionais, além da sua conexão com aumento da complexidade das redes sociotécnicas a partir do números de agentes e relações entre os mesmos; 3 ) explicitação dos procedimentos metodológicos; 4) descrição analítica dos casos através das seis características organizacionais da nova economia; 5) definição das modalidades de cálculo e das suas redes sociotécnicas em cada uma das quatro empresas estudadas; 5) considerações finais sobre os resultados alcançados na análise dos dados e as limitações desta pesquisa.

\section{REDES SOCIOTÉCNICAS E CÁLCULO ECONÔMICO}

Ao estudarem os mercados, o principal objetivo dos autores ligados à teoria do ator-rede é demonstrar o papel da rede de relações entre agentes humanos, conhecimentos, instrumentos e tecnologias, na estruturação e reprodução destes espaços sociais (CALLON, 2008; DOGANOVA; EYQUEM-RENAULT, 2009; HARDIE e MACKENZIE, 2007; ROBERTS, 2012; SAYES, 2013). Essa perspectiva amplia o conceito de redes sociais para o de redes sociotécnicas, incluindo na análise não somente as relações interpessoais como, também, as tecidas com conhecimentos e com artefatos materiais.

Segundo essa corrente, as redes sociotécnicas são compostas por relações entre agentes nãohumanos e humanos. Portanto, artefatos, tecnologias e conhecimentos são compreendidos não como meros instrumentos utilizados pelos indivíduos em suas ações, mas como entidades com capacidade de agência.

Essa perspectiva toma como pressuposto a total indeterminação da capacidade de agência dos atores, ou seja, esses não possuem a priori uma lógica de ação (CALLON, 1998, 2004; LATOUR, 1999, 2006; LAW, 1999). Nesse sentido, a capacidade de agência é exercida por coletivos híbridos, que são coletivos constituídos por dispositivos materiais e técnicos, conhecimentos e seres humanos (CALLON, 2004, 2007, 2008). Portanto, é a rede sociotécnica que estrutura certo espaço de ação e, ao fazê-lo, dota os atores sociais de determinadas capacidades de 
NORUS - v4, n.5, jan - jul 2016.

agência. Esse processo é denominado de agenciamento ${ }^{1}$ (CALLON, 2008; MUNIESA, MILLO, CALLON, 2007).

Nesta perspectiva, os agentes não-humanos que produzem agenciamentos de cálculo econômico são chamados de "dispositivos de mercado" (MUNIESA, MILLO, CALLON, 2007; ROSCOE, 2013) ou de "dispositivos ou ferramentas de cálculo" (CALLON, 1998). Esses agentes não-humanos têm capacidade de agência e são agenciamentos:

[...] these objects can be considered as objects with agency: whether they might just help (in a minimalist, instrumental version) or force (in a maximalist, determinist version), devices do things. They articulate actions; they act or they make others act. (MUNIESA, MILLO, CALLON, 2007, p. 2)

No caso da empresa no mercado de trabalho, podemos trazer a título de exemplo que os dispositivos podem ser testes lógicos, técnicas de entrevistas, sistemas informáticos e intranet de gerenciamento de recursos humanos, conhecimentos advindos da formação universitária dos profissionais de RH.

A perspectiva do ator-rede, portanto, remete a explicação da agência à noção de agenciamento, isto é, à dimensão estrutural dos mecanismos, componentes e características da rede sociotécnica que produziram as condições de possibilidade para modalidades de agência como o cálculo econômico.

Todavia, cabe perguntar: o que é exatamente o cálculo econômico? Compreendemos que um agente calcula quando ele é capaz dos seguintes procedimentos mentais: 1) listar possíveis cenários sobre a realidade (sendo cada cenário formado por uma lista de atores e produtos e uma distribuição dos últimos entre os primeiros); 2) hierarquizar esses possíveis cenários (o que evidencia o objeto e o conteúdo das preferências do agente); 3) identificar e descrever as ações necessárias para a produção de cada um dos cenários possíveis (CALLON, 1998, 2004). Denomina-se aqui essas três operações como, respectivamente, classificar, julgar e planejar.

Essa definição de cálculo econômico, por ser abstrata, permite compreender que existem variações discretas nas maneiras como agentes executam essa capacidade. Não é apenas por considerações numéricas que é possível realizar esses procedimentos necessários ao cálculo econômico. Todavia, no caso da firma no mercado de trabalho, quais são as formas concretas desses procedimentos de cálculo?

Para responder a essa pergunta, cabe destacar que as pesquisas sobre o modo como empresas realizam a sua demanda no mercado de trabalho (FERNANDEZ, CASTILLA, MOORE, 2000;

\footnotetext{
${ }^{1}$ Adaptação do original em francês agencement.

${ }^{2}$ No original, market devices.

${ }^{3}$ No original, calculative devices ou accounting tools.
} 


\section{Formas de organização da demanda de firmas de TI no mercado de trabalho}

FERNANDEZ e SOSA, 2005; MARCHAL e RIEUCAU, 2010; MARSDEN, 1994; MERLE, 2012; RIVERA, 2012 ; RUBINEAU e FERNANDEZ, 2013) afirmam que essa demanda é realizada por meio de três operações: recrutamento, seleção e contratação. Relacionando com a noção de cálculo de Callon, pode-se afirmar que recrutar consiste definir um cenário no mercado de trabalho para a realização da demanda da firma; trata-se de saber quais são os trabalhadores e o que eles ofertam. Ao fazer isso, a firma está identificando quais são os cenários possíveis de realização de sua demanda. Já selecionar trata justamente de hierarquizar esses conjuntos de trabalhadores e o que eles são capazes de ofertar em termos de força-de-trabalho vis-à-vis ao interesse da firma como demandante. Por último, a contratação é quando a firma planeja e executa um curso de ação ou o conjunto de procedimentos necessários para produção de um dos cenários possíveis em termos de realização da sua demanda.

Portanto, através da perspectiva da teoria do ator-rede é possível a construção de um modelo de análise sobre a capacidade de a firma executar o cálculo econômico. A partir dessa perspectiva, as redes são compostas de elementos que instituem a capacidade de cálculo das firmas no comparecimento ao mercado de trabalho. Por fim, a partir de Callon é possível formular uma concepção de cálculo que permita ao pesquisador identificar em processos empíricos recrutamento, seleção e contratação - a manifestação dessa capacidade.

\section{NOVA ECONOMIA, CARACTERÍSTICAS ORGANIZACIONAIS E REDES SOCIOTÉCNICAS}

É um truísmo na literatura de Ciências Sociais a afirmação de que as últimas décadas são marcadas por um profundo processo de transformação social, político e econômico, que atingiu todos os países, porém de formas e intensidades variadas. Essas observações, que se iniciaram em meados da década de 1970, abriram caminho para uma discussão sobre se estaríamos em uma nova etapa histórica, a Pós-Modernidade. Essa noção remete então para um amplo debate de periodização histórica que se estrutura em interpretações holísticas e organizadas a partir da consideração da inter-relação de fatores de natureza cultural, política e econômica.

De maneira geral, temos autores como o filósofo Fredric Jameson (1985) ou o geógrafo marxista David Harvey (1996) que defendem a ideia de que a chamada Terceira Revolução Industrial ou Científico-Tecnológica, a globalização nas suas diversas dimensões, o surgimento no campo político do neoliberalismo e uma economia centrada no consumo e nas empresas multi ou transnacionais, representam a ruptura com as características e lógica de funcionamento das sociedades modernas. Por outro lado, pesquisadores como os sociólogos Anthony Giddens (1991) 
NORUS - v4, n.5, jan - jul 2016.

Krishan Kumar (1997) analisam basicamente os mesmos processos, porém interpretam que eles não foram suficientes para a consolidação de uma etapa histórica que rompesse com a Modernidade. Para eles, o que estamos presenciando consistiria no desdobramento e intensificações de processos constituintes das sociedades de tipo moderno.

Por mais que possa ser interessante o debate colocado nesses termos, não é possível, no espaço deste artigo, explorá-lo com a atenção devida, além do risco de se perder enfoque analítico. Esse último está mais diretamente relacionado às mudanças tecnológicas e organizacionais que tiveram impacto no funcionamento da economia e no âmbito do mercado de trabalho. Basicamente, o interesse analítico desta pesquisa se liga às análises sobre o surgimento de uma nova economia capitalista que tem sido denominada de diferentes formas, conforme as chaves interpretativas e tradições intelectuais que cada autor utiliza para compreender esse processo em tela. Assim, o objetivo aqui é apenas trazer, a partir da leitura de alguns autores, os traços reconhecidos como mais ou menos comuns dessa nova economia, especialmente aqueles que impactam mais diretamente nas firmas, pois estas constituem a unidade de análise desta pesquisa.

Já na década de 1970, o sociólogo Daniel Bell (1973) defendia a tese da formação de uma nova economia capitalista baseada na predominância das atividades de serviços em relação às industriais e assentada numa lógica econômica na qual o uso e produção de conhecimento e informação seriam estratégicos em razão da maior importância da inovação em relação ao investimento em capital e energia visando ganhos de produtividade em escala.

Para esse sociólogo norte-americano havia uma clara tendência de mudança para uma nova etapa do capitalismo, isto é, um movimento de mudança que partia do capitalismo industrial para o pós-industrial. No primeiro (que estaria sendo crescentemente substituído em razão de uma terceira revolução tecnológica) o desenvolvimento e lógica de funcionamento da economia estavam baseados na produção em massa de bens industriais, na qual era estratégico para empresas fazer mais com menos custos nos insumos de matéria-prima, energia e trabalho (ganho de produtividade em escala). A economia industrial, então, teria o setor secundário (a indústria e a manufatura) como setor econômico líder do desenvolvimento. Esse setor estruturava-se ao redor de grandes empresas organizadas hierárquica e burocraticamente, que predominante empregavam trabalhadores semiqualificados.

Em contraste, na economia pós-industrial é a inovação, baseada no conhecimento e na informação, o determinante estratégico para as empresas e para geração de riqueza e crescimento econômico. Com os avanços tecnológicos, especialmente nas áreas da informática e da telecomunicação, Bell apontava para o aumento do emprego de mão de obra mais qualificada e, 


\section{Formas de organização da demanda de firmas de TI no mercado de trabalho}

portanto, mais adequada para lidar com as novas tecnologias e a produção de inovação. Esse processo produziria uma mudança profunda na estrutura ocupacional das sociedades na direção do aumento dessa classe de profissionais mais qualificados (especialmente os com formação de nível universitário e experiência em pesquisa científica) em relação aos trabalhadores semiqualificados da economia industrial. Por fim, o setor de serviços tomaria o lugar do tradicional setor industrial, ou seja, a Revolução Tecnológica, que estaria alavancando todo esse processo de mudança, traria consigo a tendência de colocar no centro do desenvolvimento econômico capitalista a produção de serviços e bens intangíveis ${ }^{4}$.

Daniel Bell produziu sua teoria em meio a um contexto ainda embrionário de desenvolvimentos das principais tecnologias que dariam "o tom" para o surgimento e estruturação de uma nova economia. Entretanto, muitos de seus insights ainda permanecem e inspiram as análises de outros autores contemporâneos. Entre esses insights queremos aqui destacar a ascensão da importância das atividades econômicas de serviços; o aumento da demanda por uma força-detrabalho mais qualificada; mudanças nas empresas no sentido de se afastarem cada vez mais de modelos marcados pela gestão centralizada, hierarquizada e burocratizada; e o aumento de importância estratégica das atividades de inovação e das tecnologias de informação e comunicação.

Com relação a esse último aspecto, alguns anos depois de Daniel Bell, mas seguindo uma linha mais próxima ao determinismo tecnológico na economia, nós encontramos a teoria de Yoneji Masuda (1982). Para ele são as inovações tecnológicas as principais responsáveis pelas mudanças macroscópicas nos modelos econômicos das sociedades, pois as novas tecnologias são difundidas e combinadas constituindo o que ele chama de "sistemas tecnológicos" que, por sua vez, consolidam novas maneiras e um novo nível de produtividade, assim transformando a sociedade e a economia como um todo.

Nessa perspectiva, a sociedade e a economia industrial seriam frutos principalmente das inovações tecnológicas - inicialmente através da máquina a vapor e após pelas máquinas eletromecânicas - atuantes na ampliação da capacidade produtiva do trabalho humano voltado para produção de bens industriais tangíveis e do consumo de massa. Já a nova etapa econômica e social, denominada por Masuda como "sociedade da informação", seria fruto do surgimento das tecnologias de informação e comunicação (o que o autor chama de "teleinformática") que direcionariam os padrões de produtividade econômica para a ampliação do trabalho mental humano. Essas tecnologias formariam um sistema tecnológico baseado na computação, bancos de dados e

\footnotetext{
${ }^{4}$ Cabe destacar que, Daniel Bell não estava defendendo a ideia do fim do industrialismo, mas apenas que o crescimento da economia capitalista não seria mais determinado pela produção de bens industriais, mas pela produção de serviços e bens intangíveis através de processos produtivos baseados no uso do conhecimento e da informação visando à inovação e não mais o descobrimento empírico.
} 
NORUS - v4, n.5, jan - jul 2016.

redes de informação e comunicação. As forças produtivas formadas por esse sistema tecnológico estariam, então, voltadas para a produção de bens intangíveis e serviços informacionais.

Por mais esquemática e adesista ao determinismo tecnológico, a perspectiva de Masuda fornece a este estudo uma pista analítica com "tintas mais fortes”, mas que Daniel Bell (1973) já mencionava sobre a nova economia: a competição e a produtividade estão crescentemente orientadas por tecnologias que são baseadas e simultaneamente atuam na produção e distribuição de conhecimento e informação. É esse vínculo entre um novo paradigma tecnológico baseado nas tecnologias de informação e comunicação e a formação de uma nova economia capitalista que interessa esta pesquisa, pois desse modo se torna compreensível o significado de mudanças importantes que operam nas esferas dos diferentes mercados, nas experiências laborais de trabalhadores e profissionais e também nas estratégias comerciais e nos modelos de gestão desenvolvidos pelas firmas em meio a esse cenário de profunda transformação econômica e social. Em outros termos,

Este processo desencadeado por mudanças no paradigma tecnológico, em grande parte decorrente da difusão das tecnologias de informação e comunicação (TICs), foi acompanhado de mudanças em outras dimensões como: elevação do nível de escolaridade da força de trabalho, do crescimento do setor de serviços, em especial, serviços intensivos em conhecimento, da crescente participação feminina no mercado de trabalho. Em consequência, o mundo do trabalho é afetado de forma significativa, tanto no que se refere à produção propriamente dita, quanto às formas de organização do trabalho, às relações de trabalho, às demandas do mercado de trabalho (GUIMARÃES, 2009, p. 8).

Portanto, essas mudanças provocadas pelas tecnologias de informação e comunicação têm consequências profundas e dinâmicas nos mercados, nas empresas e no trabalho. No caso deste estudo, mais especificamente, pretende-se contribuir na compreensão dessa nova economia, olhando o cálculo econômico que as firmas realizam ao comparecer no mercado de trabalho. Desse modo, torna-se analiticamente estratégico destilar, a partir dos autores que se debruçaram sobre o processo de surgimento da nova economia capitalista, as principais características e forças que impactam e simultaneamente são transformadas pela ação dos agentes econômicos na nova economia.

Dentre os autores contemporâneos, destacam-se os estudos de Manuel Castells que conferem centralidade a essa relação entre mudança econômica e transformações nos paradigmas tecnológicos. Para esse sociólogo, a nova economia ou, nos seus termos, o "capitalismo informacional" é constituído por processos provocados e sustentados pelas mudanças no paradigma tecnológico das sociedades através da emergência, desenvolvimento e disseminação das tecnologias de informação e comunicação. Para Castells essa transformação tecnológica não somente conferiu ao capitalismo um novo modelo de desenvolvimento (o "informacionismo") como também operou 


\section{Formas de organização da demanda de firmas de TI no mercado de trabalho}

transformações profundas em várias esferas, configurando uma nova estrutura social (a "Sociedade em Rede") e um novo período histórico (a "Era da Informação").

By Information Age I refer to a historical period in which human societies perform their activities in a technological paradigm constituted around microelectronics-based information/communication technologies, and genetic engineering. It replaces/subsumes the technological paradigm of the Industrial Age, organized primarily around the production and distribution of energy (CASTELLS, 2000, p. 5-6).

Interessa aqui os aspectos mais ligados à economia e ao mundo do trabalho associados ao desenvolvimento da Sociedade em Rede e da Era da Informação - para usar a terminologia de Castells. Nesse sentido, um dos primeiros elementos que se deve destacar é a tese do autor sobre como o novo paradigma tecnológico, centrado nas tecnologias de informação e comunicação, encontra-se amalgamado com a maneira como o desenvolvimento se processa na nova economia.

\footnotetext{
No novo modo informacional de desenvolvimento, a fonte de produtividade acha-se na tecnologia de geração de conhecimentos, de processamento da informação e de comunicação de símbolos. Na verdade, conhecimento e informação são elementos cruciais em todos os modos de desenvolvimento [...]. Contudo, o que é específico ao modo informacional de desenvolvimento é a ação de conhecimento sobre os próprios conhecimentos como principal fonte de produtividade. O processamento da informação é focalizado na melhoria da tecnologia do processamento da informação como fonte de produtividade, em um círculo virtuoso de interação entre as fontes de conhecimentos tecnológicos e a aplicação da tecnologia para melhorar a geração de conhecimentos e o processamento da informação (CASTELLS, 2007, p. 53-54).
}

Neste momento, Castells se alinha com Daniel Bell (1973) e Yoneji Masuda (1982) ao destacar que, no que ele chama de "modo informacional de desenvolvimento", o funcionamento da economia passa a estar centrado na capacidade de geração de novas tecnologias que atuem na produção, processamento e circulação do conhecimento e da informação; diferente do capitalismo industrial movido pelos investimentos em fontes de energias e pelo incremento no uso de capital físico no processo produtivo. Por isso mesmo, ressalta Castells, se antes o conhecimento só tinha valor por sua aplicação em tecnologias que maximizassem a produtividade, no capitalismo informacional, ele importa por sua capacidade de desenvolver tecnologias propulsoras da produção e processamento da própria informação e conhecimento; daí a centralidade e protagonismo das tecnologias da informação e comunicação. Esse modelo de desenvolvimento, associado pela emergência de um paradigma tecnológico baseado nas tecnologias de informação e conhecimento, produz uma nova economia, porém essa é ainda essencialmente uma economia capitalista, "but it is a new brand of capitalism, in which rules for investment, accumulation, and reward, have substantially changed" (CASTELLS, 2000, p. 11).

Como não poderia ser diferente, esse novo funcionamento da economia do capitalismo informacional também exige uma nova forma organizacional para se operar dentro dela, a saber, a 
NORUS - v4, n.5, jan - jul 2016.

"empresa em rede" (CASTELLS, 2007, p. 209-259). As firmas, segundo essa perspectiva, afastamse do modelo fordista-taylorista, que basicamente consiste em processos mecanizados de produção padronizada em linhas de montagens que são geridas a partir dos princípios da integração vertical e da alta fragmentação e especialização técnica do trabalho. Esse modelo fundamentou-se na busca por ganhos de produtividade em economias de escala (PEREIRA e OLIVEIRA, 2001).

A nova economia põe em xeque esse modelo porque a sobrevivência nos mercados passa estar mais ligada ao atendimento de demandas mundialmente diversificadas, baseadas na qualidade dos produtos e na rápida transformação tecnológica. Assim sendo, a empresa em rede é antes de tudo uma empresa que busca a flexibilidade dos seus processos produtivos e da gestão. Castells mostra como essa flexibilidade foi planejada e implantada por diferentes maneiras a depender dos contextos institucionais, culturais e históricos em que estão situadas as organizações que buscaram se adaptar aos novos condicionantes da nova economia.

Entretanto, correndo o risco da simplificação, pode-se afirmar que a flexibilidade foi buscada nas organizações através das reduções de hierarquias administrativas e da descentralização da gestão, por meio do trabalho em grupo e por projetos e da focalização nos processos diretamente relacionados à atividade-fim. Ainda cabe mencionar que as empresas elaboraram suas estratégicas comerciais visando a nichos de mercado, também seus modelos de gestão buscam por maior envolvimento por parte dos trabalhadores nas diferentes atividades exercidas dentro da firma. Tudo isso foi propiciado e se relacionou com o uso, aperfeiçoamento e integração das tecnologias de informação e comunicação. Desse modo, a empresa em rede é o resultado desse complexo processo de mudança e reestruturação organizacional, ocorridos especialmente nas décadas de 1980 e 1990, que moldou e foi moldado pelas tecnologias de informação e comunicação.

Em suma, a literatura sobre nova economia tem destacado como típicas desse contexto, as seguintes características organizacionais: 1) se na etapa econômica anterior o paradigma de organização era a indústria voltada para o consumo de massa, na nova economia são atividades de serviços do segmento de tecnologias da informação que se tornam paradigmáticas; 2) a dinâmica competitiva e as estratégias comerciais das firmas se voltam para o aprimoramento de suas capacidades e o envolvimento sistemático em processos de inovação; 3) as relações de emprego e a gestão do trabalho se tornam mais flexíveis e com ambientes mais informais; 4) adoção de formas de organização marcadas pelo trabalho em grupo e pela polivalência; 5) maior valorização e nível de exigência de qualificações técnicas e comportamentais; 6) em contraste com o modelo de consumo de massa, há uma relação mais personalizada entre produtores e clientes gerando a customização de produtos e serviços. 


\section{Formas de organização da demanda de firmas de TI no mercado de trabalho}

Por fim, Michel Callon destaca um aspecto da nova economia que foi pouco ou nada analisado pelos atores mencionados até aqui, a saber, o papel estratégico para as empresas na nova economia de desenvolverem a habilidade de se relacionarem e colaborarem com um conjunto cada vez maior, numérica e qualitativamente, de agentes humanos e não-humanos externos à empresa. Esse autor denomina a nova economia como "economia de qualidades" (CALLON, 2007; CALLON; MÉADEL; RABEHARISOA, 2002) cujo aspecto distintivo é a importância crescente que assumem a inovação e a interação entre empresas e consumidores no funcionamento dos mercados. Ambos têm exigido das empresas a capacidade de envolver agentes externos a elas nos processos de produção e comercialização dos seus bens. A necessidade de inovação constante e acelerada, imposta pelo novo contexto econômico, exige dos agentes, especialmente empresas, a maior mobilização de recursos de conhecimento e informação que dificilmente encontram-se acessíveis internamente. Assim, para inovar, os agentes econômicos precisam estrategicamente "se abrir" para um número crescente de relações sociotécnicas com outros agentes em projetos de interesse comum entre seus participantes (CALLON, 2007).

Em suma, o argumento dessa perspectiva (CALLON, 2007; CALLON; MÉADEL; RABEHARISOA, 2002) consiste em afirmar que quanto mais estratégico se torna o processo de inovação tanto mais os agentes econômicos precisam estabelecer relações sociotécnicas extensas e complexas com diferentes tipos de agentes. Nesse sentido, as tecnologias de informação e comunicação, tal como nas demais perspectivas vistas, assumem uma posição de destaque e estratégica. Para Michel Callon, elas serviriam justamente para ampliar essa capacidade de interação e coordenação entre diferentes tipos de agentes (CALLON, 2007; CALLON; MÉADEL; RABEHARISOA, 2002).

O que se pretende aqui é justamente verificar como se processam e quais relações sociotécnicas as firmas estabelecem em ordem de poder calcular o insumo que demandam (a forçade-trabalho) quando comparecem no mercado de trabalho. E é também por essa importância que assumem as tecnologias da informação em praticamente todas as perspectivas que se propuseram em compreender a nova economia, que se elegeu tomar como objeto empírico de análise, as firmas que desenvolvem produtos e serviços referentes a essas tecnologias. Portanto, a análise empírica dessas empresas pode proporcionar um ponto de vista analiticamente privilegiado para compreender o funcionamento, os condicionantes e as formas que assumem a organização da rede socioténica para o cálculo econômico sobre um dos insumos indispensáveis para qualquer atividade econômica, o trabalho. 
NORUS - v4, n.5, jan - jul 2016.

\section{PROCEDIMENTOS METODOLÓGICOS}

A metodologia de pesquisa adotada foi o estudo de caso (GERRING, 2007) voltado para análise qualitativa de dados. Portanto, foi realizado um levantamento sistemático e aprofundado de dados sobre cada caso (no total quatro), limitado ao grau de autorização de acesso a documentos e pessoas permitidos pelas empresas.

Os casos estudados são de firmas de tecnologias da informação. O objetivo foi o de investigar a natureza do cálculo econômico executado pela firma no mercado trabalhado, a partir das condições engendradas pelas suas relações sociotécnicas. Nesse sentido, não se está estudando o mercado de trabalho, nem as relações de trabalho e tão pouco o processo produtivo no setor de TI.

A seleção dos casos foi baseada na importância da empresa como demandante no mercado de trabalho, configurando-se, por isso mesmo, como uma organização de médio ou grande porte em termos do efetivo de funcionários. Outro elemento importante de seleção de casos foi uma preferência por firmas com atuação reconhecida e de peso no mercado de produtos de TI. Procuraram-se casos que também fossem diferentes em termos dos segmentos de atuação no setor de TI, para com isso ter em conta variações de uma mesma sorte de fenômeno. Assim se chegou ao estudo de um caso no segmento de indústria e manufatura e três tipos de empresas de serviços de software.

A próxima seção consiste numa descrição analítica dos casos; por conseguinte, vale aqui uma breve caracterização dos quatro casos pesquisados:

a) indústria e manufatura de hardware de transmissão de dados, voz e imagem. Firma localizada na região metropolitana de Porto Alegre (RMPA) que possui mais de 200 funcionários, sendo a quase totalidade dedicada à atividade-fim. Trata-se de uma empresa nacional e com atuação tradicional e pioneira no mercado brasileiro de TI. Para preservar o seu anonimato foi denominada de "EC1";

b) empresa cuja atuação se faz no desenvolvimento de softwares personalizáveis de gestão empresarial e também exerce a função de suporte ao cliente. A unidade pesquisada está localizada na RMPA e conta com mais de 500 funcionários, sendo que a quase totalidade deles exerce funções diretamente ligadas à atividade-fim da empresa. Trata-se de uma empresa internacional com atuação global e posição predominante no mercado mundial e nacional no segmento do seu produto. Chamase essa empresa de "EC2";

c) firma de desenvolvimento de softwares personalizáveis também para áreas de gestão de empresas. Localizada em Porto Alegre, a unidade conta com quase 300 
Formas de organização da demanda de firmas de TI no mercado de trabalho

funcionários, a maioria dos quais é envolvida na atividade-fim. Possui atuação nacional e na América Latina, principalmente tendo como clientes pequenas e médias empresas. Foi denominada aqui de "EC3";

d) consultoria e desenvolvedora de software por encomenda para empresas e organizações. Localizada em Porto Alegre, a unidade conta com pouco mais de 100 funcionários com a quase totalidade deles atuando na atividade-fim. A empresa possui atuação global com segmentação no mercado de projetos de software de alta complexidade para grandes clientes corporativos. Denominou-se de "EC4".

Em um primeiro momento foi feita a coleta de dados através de entrevistas semiestruturadas, privilegiando diretores de recursos humanos e pessoas atuantes nas funções de recrutamento e seleção. Com cada uma dessas pessoas, utilizou-se o procedimento de fazer duas entrevistas, sendo a primeira, em todos os casos, realizada com base no mesmo roteiro de entrevista e, em seguida, com base em análise preliminar das respostas obtidas, foi confeccionado roteiros específicos para aprofundar pontos de maior interesse para esta pesquisa. Através das entrevistas com os gestores de RH e recrutadores foram identificados quais outros funcionários estavam envolvidos na realização da demanda da empresa no mercado de trabalho; e, desse modo, foi solicitado o contato com uma parte desses funcionários para a realização de uma entrevista. A razão de se entrevistar apenas uma vez os funcionários que não são do RH ocorreu em função da negociação sobre a autorização da nossa entrada nas empresas, que foi concedida na condição de se perturbar minimamente a rotina dos funcionários da parte técnica. Todo esse processo foi realizado entre o segundo semestre de 2011 e o primeiro semestre de 2012. O quadro abaixo resume as informações sobre os entrevistados em cada estudo de caso.

Quadro 1 - Informações de Entrevistados por Empresas.

\begin{tabular}{|l|l|l|l|l|}
\hline \multicolumn{2}{|l|}{ Setor de RH } & \multicolumn{3}{l|}{ Área Técnica } \\
\cline { 2 - 5 } Cargo do Entrevistado & $\begin{array}{l}\text { Número } \\
\text { Entrevistas }\end{array}$ & de & Cargo do Entrevistado & $\begin{array}{l}\text { Número } \\
\text { Entrevistas }\end{array}$ \\
\hline
\end{tabular}


NORUS - v4, n.5, jan - jul 2016.

\begin{tabular}{|c|c|c|c|c|}
\hline EC1 & $\begin{array}{l}\text { Diretora de RH } \\
\text { Técnica de Dep. Pessoal }\end{array}$ & $\begin{array}{l}02 \\
01\end{array}$ & $\begin{array}{l}\text { Gestor de P\&D } \\
\text { Gestor de Produção } \\
\text { Gestor de Planejamento } \\
\text { Industrial }\end{array}$ & $\begin{array}{l}01 \\
01 \\
01\end{array}$ \\
\hline EC2 & $\begin{array}{l}\text { Diretora de RH } \\
\text { Recrutadora } \\
\text { Recrutadora }\end{array}$ & $\begin{array}{l}02 \\
02 \\
02\end{array}$ & $\begin{array}{ll}\text { Gestor } & \text { de } \\
\text { Desenvolvimento } & \text { de } \\
\text { Software } & \end{array}$ & 01 \\
\hline EC3 & $\begin{array}{l}\text { Diretor de RH } \\
\text { Recrutadora }\end{array}$ & $\begin{array}{l}02 \\
02\end{array}$ & - & - \\
\hline EC4 & $\begin{array}{l}\text { Diretor de RH } \\
\text { Diretor de Escritório } \\
\text { Gestora } \\
\text { Recrutamento } \\
\text { Organizadora de } \\
\text { Seleção } \\
\text { Recrutadora } \\
\text { Recrutadora }\end{array}$ & $\begin{array}{l}01 \\
01 \\
02 \\
01 \\
02 \\
02\end{array}$ & $\begin{array}{l}\text { Analista de Teste } \\
\text { Analista de Qualidade } \\
\text { Desenvolvedor }\end{array}$ & $\begin{array}{l}01 \\
01 \\
01\end{array}$ \\
\hline
\end{tabular}

Na EC2 só foi possível fazer uma entrevista com funcionários da área técnica em razão de problemas de agenda da empresa; na EC3, em determinado momento, não se obteve mais autorização para nenhuma entrevista além de quatro com duas pessoas vinculadas ao RH, alegandose que a empresa estava passando por um momento de mudanças operacionais e contratações para atender novos clientes; nessas condições a pesquisa perturbaria o ritmo de trabalho.

Também através das entrevistas com as pessoas da parte de RH, identificou-se os agentes não-humanos que faziam parte da organização do cálculo da firma no mercado de trabalho. Com relação a esse tipo de dado, a coleta foi realizada seguindo dois tipos: a obtenção de cópia do material para ser analisado pelo pesquisador e a observação in loco do material. No primeiro tipo de coleta, com exceção da EC1, em todos os casos foram coletados os relatórios de avaliação de entrevistas, folders e apresentações de PowerPoint sobre a cultura da empresa e os roteiros de entrevistas. No segundo tipo, em todas as empresas observamos o sistema informático dos bancos de currículos e o site para recebimento de currículos; na EC2 e EC4, o plano de cargos, carreiras e salários disponível numa intranet, assim como os testes técnicos e psicológicos; em todas as empresas a leitura das pesquisas sobre o mercado de trabalho de TI; e, por fim, com exceção da 


\section{Formas de organização da demanda de firmas de TI no mercado de trabalho}

EC1, observamos o sistema de intranet de gestão de recursos humanos. Por razões de preservação do anonimato das fontes, nenhum desses materiais será reproduzido neste artigo.

Esse corpus de dados coletados foi submetido à técnica de análise de conteúdo categorial (BARDIN, 1979). Esse processo de análise foi operacionalizado da seguinte maneira: primeiro, o corpus de dados foi separado e agrupado de acordo ao pertencimento a cada caso. A seguir, para cada grupo de dados de cada caso foi feito separadamente e com auxílio do software NVivo (RICHARDS, 1999), a codificação de trechos de entrevistas e extratos dos documentos na seguinte grade de categorias:

- Rede Sociotécnica

○ Relações entre pessoas do RH

○ Relações entre pessoas do RH e área técnica

- Relações entre pessoas do RH e pessoas fora da firma

○ Relações entre pessoas do RH e dispositivos de cálculo

- Relações entre pessoas de área técnica e dispositivos de cálculo

- Demanda

○ Organização e gestão do trabalho

○ Estratégias e percepção da firma para o mercado de trabalho

- Perfil técnico de trabalhador demandado

- Perfil comportamental de trabalhador demandado

- Cálculo de Valor

- Métricas do cálculo

- Operações de recrutamento

○ Operações de seleção

Operações de contratação Após essa codificação foi feito o procedimento de leitura transversal, isto é, o conjunto de dados de cada caso foi analisado pela leitura dos trechos em cada categoria. Isso permitiu compreender cada um dos elementos e relações que compõem a rede sociotécnica das empresas, o perfil de suas demandas por força-de-trabalho e as operações de cálculo que se estruturam a partir das combinações entre relações sociotécnicas e esse perfil demandado.

\section{CARACTERÍSTICAS ORGANIZACIONAIS DA NOVA ECONOMIA E OS CASOS ESTUDADOS}


NORUS - v4, n.5, jan - jul 2016.

Nesta seção é feita uma caracterização sistemática com o objetivo de classificar os casostipo em termos de aproximação das seis características organizacionais tidas como típicas da nova economia. O quadro abaixo expõe esquematicamente os resultados desse esforço analítico:

Quadro 2 - Aproximação dos Casos em Relação às Características Organizacionais Típicas da Nova Economia.

\begin{tabular}{|c|c|c|c|c|}
\hline & EC1 & EC2 & EC3 & EC4 \\
\hline Serviços de TI & NÃO & SIM & SIM & SIM \\
\hline Inovação & POUCA & ALTA & ALTA & ALTA \\
\hline Gestão Flexível & NÃO & ALTA & MÉDIA & ALTA \\
\hline $\begin{array}{lr}\text { Trabalho } & \text { em } \\
\text { Grupo, } & \text { por } \\
\text { Projeto } & \text { e } \\
\text { Polivalência } & \end{array}$ & BAIXO & MÉDIO & MÉDIO & ALTO \\
\hline $\begin{array}{l}\text { Qualificação } \\
\text { Demandada }\end{array}$ & $\begin{array}{l}\text { ENSINO } \\
\text { MÉDIO OU } \\
\text { TÉCNICO }\end{array}$ & $\begin{array}{l}\text { ENSINO } \\
\text { SUPERIOR }\end{array}$ & $\begin{array}{l}\text { ENSINO } \\
\text { SUPERIOR }\end{array}$ & $\begin{array}{l}\text { ENSINO } \\
\text { SUPERIOR }\end{array}$ \\
\hline $\begin{array}{l}\text { Personalização } \\
\text { do Produto }\end{array}$ & POUCA & MÉDIA & MÉDIA & ALTA \\
\hline
\end{tabular}

No quadro acima, constata-se que o caso que mais se aproxima das características organizacionais típicas da nova economia é o EC4. Em ordem de maior para menor proximidade, podem ser classificados respectivamente, o EC2 e o EC3 e o EC1. Vejamos as dimensões de análise por caso, começando pelo eixo da "inovação", uma vez que a caracterização das empresas como sendo ou não do setor de serviços de TI foi estabelecida na seção anterior.

Não foi utilizada nesta pesquisa uma noção de inovação teoricamente fundamentada pela literatura especializada no tema. Como nosso interesse reside no cálculo econômico da firma no mercado de trabalho, elegemos por utilizar as concepções que as empresas tinham de inovação como um dos critérios na elaboração do perfil de competências que elas esperavam da sua força de trabalho, isto é, a noção de inovação foi analisada como um dispositivo de cálculo.

Nesse sentido, contatamos que apenas a EC1 se diferenciava na sua acepção de inovação. Nessa empresa, a capacidade de inovação como um tipo de qualificação do perfil de competências demandadas, estava limitada a uma tarefa específica de profissionais engenheiros eletrônicos ou de 


\section{Formas de organização da demanda de firmas de TI no mercado de trabalho}

informática da área de P\&D; quanto aos trabalhadores das demais áreas, esperava-se deles ter competências técnicas especializadas do processo produtivo.

Em contraste, nas demais empresas estudadas, a inovação era tida como um elemento constitutivo do modelo organizacional e da cultura da empresa, assim como uma competência comportamental que a maior parte dos funcionários deveria possuir. Assim, a inovação era considerada como uma postura que o profissional deveria ter para contribuir no aprimoramento dos diferentes processos produtivos e organizacionais da empresa. A inovação, nesse sentido, era percebida como uma competência comportamental relacionada a noções como criatividade, comportamento orientado para "agregar valor" à firma, preocupação para com a satisfação dos clientes e para com o aprimoramento da qualidade dos serviços ofertados e das rotinas de trabalho. Portanto, a inovação era percebida como um ativo essencial nas estratégias de mercado dessas empresas.

A EC2 e a EC4 foram os casos onde constatamos modelos mais flexíveis de gestão do trabalho. Nessas duas empresas, não havia controle sobre a jornada de trabalho dos funcionários, esses eram supervisionados apenas pela conclusão de projetos dentro dos prazos estabelecidos. Essas empresas, então, não tinham ponto eletrônico, isto é, desde que o profissional apresentasse o resultado esperado, ele poderia trabalhar nos horários que preferisse ou em casa. Essas empresas possuíam ambientes informais de trabalho com trabalhadores vestindo bermuda e camiseta dentro da empresa; ambientes de socialização e descanso para os funcionários, por exemplo, salas de jogos e poltronas reclináveis; ambientes que não estavam divididos em estações individuais de trabalho, privilegiando-se ambientes abertos e salas de reuniões para grupos; políticas de reduções de hierarquias e processos burocráticos, valorizando a capacidade dos próprios trabalhadores em gerir suas tarefas.

Em contraste, na EC3, há um ambiente mais formal e uma gestão do trabalho menos flexível: formas de se vestir tradicionais, estações de trabalho individuais, exigência de jornadas de trabalho através de ponto eletrônico e a presença de processos hierárquicos e burocráticos de supervisão e comunicação entre os profissionais e gestores. Por último, a EC1 se apresentou como uma empresa típica do ramo industrial: separação clara entre os níveis de "chão de fábrica" e da gestão, jornadas fixas de trabalho, funcionários da produção devidamente uniformizados, ocupando estações individuais de trabalho e executando tarefas especializadas.

Em razão desse modelo de gestão, a EC1 não demandava de seus funcionários atuação polivalente no processo produtivo e o trabalho em grupo estava limitado à equipe de P\&D. Os 
NORUS - v4, n.5, jan - jul 2016.

gestores técnicos de chão de fábrica valorizavam tanto o saber técnico especializado como o adquirido ao longo da experiência profissional em um ofício específico.

Como empresa mais próxima da nova economia, na EC4 foi constatada que era valorizada a capacidade de aprendizado e interesse em novos saberes técnicos como o domínio de diferentes linguagens de programação. Por ser uma empresa de consultoria com projetos específicos para cada cliente, a EC4 valorizava profissionais com capacidade em interagir com diferentes tecnologias, pois cada cliente é um projeto e, por isso, cada projeto poderia demandar o uso de diferentes linguagens de programação, conhecimento da realidade de negócios do cliente e até mesmo capacidade de comunicação para interagir com esse último. Assim sendo, os projetos por clientes determinavam o uso de processos de trabalho em grupo singulares (um projeto, um grupo diferente) no qual a supervisão e gestão hierárquica eram mínimas. Ademais, todas as atividades que compõem o processo de desenvolvimento de softwares eram feitas no sistema de "pareamento", ou seja, sempre dois profissionais dividindo o mesmo computador. Em suma, por ser uma empresa que trabalha por projetos singulares para cada cliente, a EC4 valorizava competências técnicas e comportamentais relacionadas à capacidade de trabalho em grupo e à polivalência.

Na EC2 e EC3, constatamos que havia formas de trabalho em grupo, porém adotadas a partir de um modelo mais moderado, quando comparado ao da EC4. Na EC2 e EC3, os grupos eram divididos de acordo com a divisão do trabalho, por exemplo, grupos da tarefa de teste de software, outros ligados à codificação nas linguagens de programação utilizadas pelas empresas ${ }^{5}$ e outros em atividades de suporte ao cliente. Ademais, na EC2 e EC3, os profissionais tinham seus equipamentos e postos de trabalho individuais. Podemos resumir que na EC2 e EC3 havia trabalho em grupos organizados conforme especialidades e polivalência limitada; enquanto que, na EC4, o trabalho era em grupos compostos por profissionais de diferentes áreas técnicas e com alto grau de valorização da polivalência.

A maior parte dos funcionários da EC1 compõe o chão de fábrica. Assim sendo, essa empresa, em geral, exigia como qualificação o ensino médio ou ensino técnico. Algumas atividades do chão de fábrica, essa exigência mínima de escolaridade poderia ser substituída pela experiência de trabalho. A exceção eram os funcionários do setor de $\mathrm{P} \& \mathrm{D}$, que eram compostos de engenheiros com formação mínima de nível superior, nas áreas da eletrônica e informática. Nas demais empresas, o nível de escolaridade mínima exigida era superior completo ou em vias de conclusão e a fluência na língua inglesa como requisito na totalidade dos cargos das empresas. Com exceção da

\footnotetext{
${ }^{5}$ Esta é outra diferença entre a EC4 e a EC2 e a EC3: enquanto que na primeira utilizavam-se diferentes linguagens de programação, nas duas últimas eram utilizados apenas dois tipos de linguagens de programação para o desenvolvimento dos produtos de software dessas empresas.
} 


\section{Formas de organização da demanda de firmas de TI no mercado de trabalho}

EC1, todas as firmas estudadas possuíam exigências de qualificações comportamentais, por exemplo, capacidade de relação com o cliente, de trabalhar em grupo, de aprendizado, entre outras.

Por fim, no que concerne ao aspecto "personalização do produto", constatamos que a EC4 é a empresa que possui este elemento de maneira marcante, pois ela trabalha no desenvolvimento de um software específico para cada cliente, isto é, a personalização total do produto. Nos casos da EC2 e EC3, verificamos que essas empresas trabalham com um modelo de desenvolvimento de softwares customizáveis, ou seja, elas possuem um produto padronizado que é customizado de acordo com o cliente ou com a realidade nacional onde o software é vendido. Em contraste, a EC1 apresenta quase nenhum grau de personalização dos seus produtos. O que ocorre nesse caso é que a EC1 se reúne com diretores de tecnologias de grandes empresas e potenciais clientes da EC1. A partir dessas reuniões, a EC1 desenvolve produtos padronizados de acordo com as tendências tecnológicas determinadas pelas grandes empresas do setor de TI e telecomunicações.

A partir dessa descrição analítica dos casos-tipo é possível constatar que a EC1 é a empresa mais distante das características organizacionais típicas da nova economia, a começar pelo fato de ser uma indústria de TI; portanto, ela já se distancia do tipo de atividade considerada paradigmática na nova economia, a saber, os serviços. Compreendemos que o segmento industrial apresenta limitações em razão da natureza do seu processo produtivo que, talvez, exige um modelo organizacional mais "tradicional”. Apenas aventamos como hipótese essa questão, pois o caso EC1 apresenta particularidades organizacionais que se mostram relevantes no afastamento deste casotipo em relação à nova economia. Uma dessas particularidades é o fato de que na EC1, o setor de RH se encontrava, quando da realização do trabalho de campo, em fase de consolidação: anteriormente, a empresa apenas possuía um departamento de pessoal, encarregado somente do encaminhamento burocrático de questões como os pedidos de licença médica e registros de carteira de trabalho. Um RH em formação implicou que as práticas de gestão flexível da força de trabalho não estivessem no horizonte organizacional da EC1 ou, ainda, que os perfis de competências técnicas e comportamentais valorizados pelas empresas, não estivessem elaborados em um plano de cargos, funções e salários.

Constatamos também que o fato da EC1 ser uma empresa de propriedade e gestão familiar teve impacto no seu maior afastamento com relação às características organizacionais da nova economia. Nos relatos de entrevistas, o modelo organizacional da EC1 era descrito como intimamente relacionado à figura do fundador da empresa; este era descrito como um indivíduo precursor do setor de TI no Brasil, pois iniciou o empreendimento e o desenvolvimento dos primeiros produtos da EC1 através de parceira com uma Universidade - algo pioneiro no final da 
NORUS - v4, n.5, jan - jul 2016.

década de 1970. Todavia, o modelo de gestão da EC1, em razão do perfil do seu fundador, consolidou-se tal como outras empresas tradicionais do segmento industrial eletrônico: processo produtivo centrado em produtos padronizados, maior parte da força de trabalho de nível técnico e especializada em tarefas de montagem e teste de componentes eletrônicos e a gestão do processo de trabalho hierarquizada. Em meados dos anos 2000, houve o falecimento do fundador da empresa e a presidência da EC1 passa para a sua filha e, além disso, o seu marido se torna diretor geral de produção. Os dois, então, começaram operar mudanças de modernização na gestão e na estratégia comercial e tecnológica, porém essas mudanças ainda estavam em fase de elaboração ou implementação. Portanto, esses aspectos também contribuíram para que a EC1 se afaste da nova economia.

Relacionado ao tipo de propriedade das empresas estudadas, percebemos que a maior proximidade dos casos-tipo em relação à nova economia, variava de acordo com os tipos de propriedade das empresas: as mais próximas da nova economia, EC2 e EC4, eram firmas multinacionais com unidades ao redor do globo; depois temos a EC3 que consistia numa empresa nacional com unidades na América Latina; e por último e mais afastada da nova economia, a EC1 com uma propriedade familiar e apenas uma unidade localizada na RMPA. Cogitamos, assim, uma relação entre a proximidade com a nova economia e o grau de atuação globalizada das firmas.

Em suma, aventamos a hipótese de que o grau de proximidade de uma empresa em relação às características organizacionais da nova economia dependa de uma interação entre o setor de atividade econômica que a empresa atua e particularidades organizacionais como o grau de consolidação do RH e de atuação global da empresa, assim como o modelo de propriedade.

\section{REDES SOCIOTÉCNICAS E CÁLCULO ECONÔMICOS DE QUATRO EMPRESAS DE TI}

Nos estudos de caso, identificamos as relações sociotécnicas nas quais as quatro firmas de TI se assentam para exercerem a sua capacidade de cálculo no mercado de trabalho. Não fizemos o levantamento de todas as relações sociotécnicas que as firmas travam, mas somente aquelas que estruturam as suas condições de possibilidade de exercício do cálculo econômico no mercado de trabalho.

Esquematicamente, os quadros de 3 a 6 apresentam as redes sociotécnicas das firmas estudadas, com seus agentes humanos e dispositivos de cálculo, distribuídos segundo as operações que conformam o cálculo econômico no mercado de trabalho. 
Formas de organização da demanda de firmas de TI no mercado de trabalho

Quadro 3 - Rede Sociotécnica e Operações de Cálculo Econômico no Caso EC1.

\begin{tabular}{|c|c|c|c|c|c|}
\hline & & $\begin{array}{l}\text { Planejamento } \\
\text { da Demanda }\end{array}$ & Recrutamento & Seleção & Contratação \\
\hline \multirow{5}{*}{ 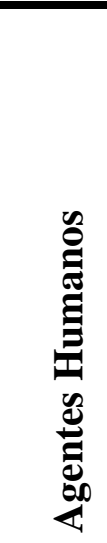 } & $\begin{array}{l}\text { Direção Executiva e } \\
\text { Comercial }\end{array}$ & $\sqrt{ }$ & & & $\sqrt{ }$ \\
\hline & $\begin{array}{lll}\text { Gestores } & \text { de } & \text { Áreas } \\
\text { Técnicas } & & \end{array}$ & $\sqrt{ }$ & $\sqrt{ }$ & $\sqrt{ }$ & $\sqrt{ }$ \\
\hline & Coornadora de RH & $\sqrt{ }$ & $\sqrt{ }$ & $\sqrt{ }$ & $\sqrt{ }$ \\
\hline & $\begin{array}{l}\text { Técnica de Departamento } \\
\text { de Pessoal }\end{array}$ & $\sqrt{ }$ & & & \\
\hline & $\begin{array}{l}\text { Profissionais da Área } \\
\text { Técnica }\end{array}$ & & $\sqrt{ }$ & & \\
\hline \multirow{8}{*}{ 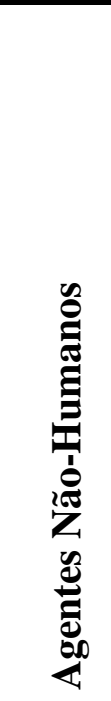 } & Tabela de Salários & $\sqrt{ }$ & & & \\
\hline & Programa de Benefícios & $\sqrt{ }$ & & & \\
\hline & $\begin{array}{l}\text { Entrevista } \\
\text { Técnica/Profissional }\end{array}$ & & & $\sqrt{ }$ & \\
\hline & Site da Empresa & & $\sqrt{ }$ & $\sqrt{ }$ & \\
\hline & Currículos & & $\sqrt{ }$ & $\sqrt{ }$ & \\
\hline & Banco de Currículos & & $\sqrt{ }$ & $\sqrt{ }$ & \\
\hline & Universidades & & $\sqrt{ }$ & & \\
\hline & $\begin{array}{llll}\text { Sites de } & \text { Vagas } & \text { de } \\
\text { Emprego } & & \end{array}$ & & $\sqrt{ }$ & & \\
\hline Total & 13 & 6 & 8 & 6 & 3 \\
\hline
\end{tabular}


NORUS - v4, n.5, jan - jul 2016.

Quadro 4 - Rede Sociotécnica e Operações de Cálculo Econômico no Caso EC2.

\begin{tabular}{|c|c|c|c|c|c|}
\hline & & $\begin{array}{l}\text { Planejamento } \\
\text { da Demanda }\end{array}$ & Recrutamento & Seleção & Contratação \\
\hline \multirow{7}{*}{ 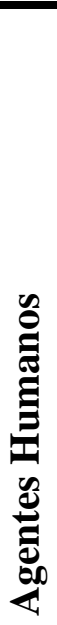 } & $\begin{array}{l}\text { Direção Executiva e } \\
\text { Comercial }\end{array}$ & $\sqrt{ }$ & & & \\
\hline & $\begin{array}{l}\text { Gestores de Áreas } \\
\text { Técnicas }\end{array}$ & $\sqrt{ }$ & & $\sqrt{ }$ & $\sqrt{ }$ \\
\hline & Coornadora de RH & $\sqrt{ }$ & & & $\sqrt{ }$ \\
\hline & Recrutadoras & & $\sqrt{ }$ & $\sqrt{ }$ & $\sqrt{ }$ \\
\hline & Diretor de Escritório & $\sqrt{ }$ & & & \\
\hline & Conselho de Acionistas & $\sqrt{ }$ & & & \\
\hline & Funcionários Técnicos & & & $\sqrt{ }$ & \\
\hline \multirow{15}{*}{ 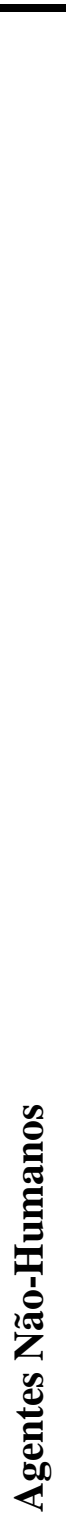 } & Pesquisa de Salários & $\sqrt{ }$ & & & \\
\hline & Programa de Benefícios & & $\sqrt{ }$ & & \\
\hline & $\begin{array}{l}\text { Plano de Cargos e } \\
\text { Carreiras }\end{array}$ & $\sqrt{ }$ & & & $\sqrt{ }$ \\
\hline & $\begin{array}{l}\text { Plano de Cargos e } \\
\text { Salários }\end{array}$ & $\sqrt{ }$ & & & $\sqrt{ }$ \\
\hline & $\begin{array}{l}\text { Sistema Informático de } \\
\text { Gestão de RH }\end{array}$ & $\sqrt{ }$ & $\sqrt{ }$ & $\sqrt{ }$ & $\sqrt{ }$ \\
\hline & $\begin{array}{l}\text { Teste de } \quad \text { Exercício } \\
\text { Técnico }\end{array}$ & & & $\sqrt{ }$ & \\
\hline & Testes Lógicos & & & $\sqrt{ }$ & \\
\hline & $\begin{array}{l}\text { Testes Psicológicos de } \\
\text { Perfil Profissional }\end{array}$ & & & $\sqrt{ }$ & \\
\hline & $\begin{array}{l}\text { Entrevista } \\
\text { Técnica/Profissional }\end{array}$ & & & $\sqrt{ }$ & \\
\hline & $\begin{array}{l}\text { Entrevista } \\
\text { Comportamental }\end{array}$ & & & $\sqrt{ }$ & \\
\hline & Cultura da Empresa & & & $\sqrt{ }$ & \\
\hline & $\begin{array}{ll}\text { Programas } & \text { de } \\
\text { Recomendação } & \end{array}$ & & $\sqrt{ }$ & & \\
\hline & Site da Empresa & & $\sqrt{ }$ & & \\
\hline & $\begin{array}{l}\text { Formulários } \quad \mathrm{de} \\
\text { Assessment }\end{array}$ & & & $\sqrt{ }$ & $\sqrt{ }$ \\
\hline & Currículos & & $\sqrt{ }$ & $\sqrt{ }$ & \\
\hline
\end{tabular}


Formas de organização da demanda de firmas de TI no mercado de trabalho

\begin{tabular}{|l|l|l|l|l|l|}
\hline & Banco de Currículos & & $\sqrt{ }$ & $\sqrt{ }$ & \\
\hline & $\begin{array}{l}\text { Sites de Redes } \\
\text { Profissionais }\end{array}$ & & $\sqrt{ }$ & & \\
\cline { 2 - 6 } & Sites de Redes Sociais & & $\sqrt{ }$ & & \\
\cline { 2 - 7 } & Universidades & & $\sqrt{ }$ & & \\
\hline & Técnica de Entrevista & & & $\sqrt{ }$ & \\
\hline & $\begin{array}{l}\text { Sites de Vagas de } \\
\text { Emprego }\end{array}$ & & $\sqrt{ }$ & $\mathbf{1 4}$ & $\mathbf{7}$ \\
\hline Total & $\mathbf{2 8}$ & $\mathbf{9}$ & $\mathbf{1 1}$ & $\mathbf{1 4}$ & \\
\hline
\end{tabular}

Quadro 5 - Rede Sociotécnica e Operações de Cálculo Econômico no Caso EC3.

\begin{tabular}{|c|c|c|c|c|c|}
\hline & & $\begin{array}{l}\text { Planejamento } \\
\text { da Demanda }\end{array}$ & Recrutamento & Seleção & Contratação \\
\hline \multirow{5}{*}{ 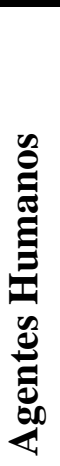 } & $\begin{array}{l}\text { Direção Executiva e } \\
\text { Comercial }\end{array}$ & $\sqrt{ }$ & & & \\
\hline & $\begin{array}{l}\text { Gestores de } \\
\text { Técnicas }\end{array}$ & $\sqrt{ }$ & & $\sqrt{ }$ & $\sqrt{ }$ \\
\hline & Coornador de RH & $\sqrt{ }$ & & & \\
\hline & Recrutadora & & $\sqrt{ }$ & $\sqrt{ }$ & \\
\hline & Funcionários Técnicos & & & $\sqrt{ }$ & \\
\hline \multirow{8}{*}{ 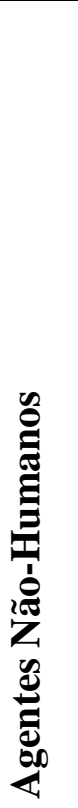 } & Pesquisa de Salários & $\sqrt{ }$ & & & \\
\hline & Programa de Benefícios & $\sqrt{ }$ & & & \\
\hline & $\begin{array}{l}\text { Sistema Informático de } \\
\text { Gestão de RH }\end{array}$ & $\sqrt{ }$ & $\sqrt{ }$ & $\sqrt{ }$ & $\sqrt{ }$ \\
\hline & $\begin{array}{lll}\text { Teste de } & \text { Exercício } \\
\text { Técnico } & & \\
\end{array}$ & & & $\sqrt{ }$ & \\
\hline & Testes Lógicos & & & $\sqrt{ }$ & \\
\hline & $\begin{array}{l}\text { Teste de Redação em } \\
\text { Português }\end{array}$ & & & $\sqrt{ }$ & \\
\hline & $\begin{array}{l}\text { Entrevista } \\
\text { Técnica/Profissional }\end{array}$ & & & $\sqrt{ }$ & \\
\hline & $\begin{array}{l}\text { Entrevista } \\
\text { Comportamental }\end{array}$ & & & $\sqrt{ }$ & \\
\hline
\end{tabular}


NORUS - v4, n.5, jan - jul 2016.

\begin{tabular}{|l|l|l|l|l|l|}
\hline \multicolumn{1}{|l|}{} & Cultura da Empresa & & & $\sqrt{ }$ & \\
\hline & Site da Empresa & & $\sqrt{ }$ & & \\
\hline & $\begin{array}{l}\text { Formulários de } \\
\text { Assessment }\end{array}$ & & & $\sqrt{ }$ & \\
\hline & Currículos & & $\sqrt{ }$ & $\sqrt{ }$ & \\
\hline & Banco de Currículos & & $\sqrt{ }$ & $\sqrt{ }$ & \\
\hline & $\begin{array}{l}\text { Sites de Redes } \\
\text { Profissionais }\end{array}$ & & $\sqrt{ }$ & & \\
\hline & Sites de Redes Sociais & & $\sqrt{ }$ & & \\
\hline & Universidades & & $\sqrt{ }$ & & \\
\hline & Técnica de Entrevista & & & $\sqrt{ }$ & \\
\hline & $\begin{array}{l}\text { Sites de Vagas de } \\
\text { Emprego }\end{array}$ & & $\sqrt{ }$ & & \\
\hline Total & $\mathbf{2 3}$ & $\mathbf{6}$ & $\mathbf{9}$ & $\mathbf{2}$ \\
\hline
\end{tabular}

Quadro 6 - Rede Sociotécnica e Operações de Cálculo Econômico no Caso EC4.

\begin{tabular}{|c|c|c|c|c|c|}
\hline & & $\begin{array}{l}\text { Planejamento } \\
\text { da Demanda }\end{array}$ & Recrutamento & Seleção & Contratação \\
\hline \multirow{8}{*}{ 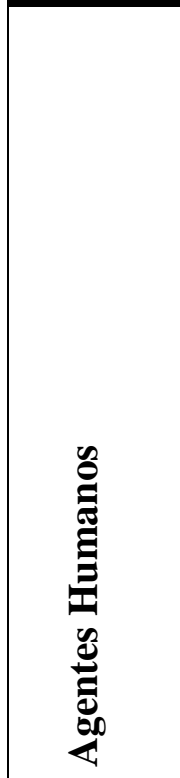 } & $\begin{array}{l}\text { Direção Executiva e } \\
\text { Comercial }\end{array}$ & $\sqrt{ }$ & & & \\
\hline & $\begin{array}{lll}\text { Gestores de Áreas } \\
\text { Técnicas }\end{array}$ & $\sqrt{ }$ & & $\sqrt{ }$ & $\sqrt{ }$ \\
\hline & Coornador de RH & $\sqrt{ }$ & & $\sqrt{ }$ & $\sqrt{ }$ \\
\hline & Recrutadores & & $\sqrt{ }$ & $\sqrt{ }$ & $\sqrt{ }$ \\
\hline & Diretor de Escritório & $\sqrt{ }$ & & $\sqrt{ }$ & $\sqrt{ }$ \\
\hline & $\begin{array}{ll}\text { Coordenadora } & \mathrm{de} \\
\text { Recrutamento } & \end{array}$ & $\sqrt{ }$ & $\sqrt{ }$ & & \\
\hline & \begin{tabular}{|ll} 
Organizadora & $\mathrm{de}$ \\
Seleção &
\end{tabular} & & $\sqrt{ }$ & $\sqrt{ }$ & \\
\hline & Funcionários Técnicos & & & $\sqrt{ }$ & $\sqrt{ }$ \\
\hline \multirow{2}{*}{ 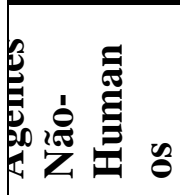 } & Programa de Benefícios & $\sqrt{ }$ & & & \\
\hline & $\begin{array}{l}\text { Plano de Cargos e } \\
\text { Carreiras }\end{array}$ & $\sqrt{ }$ & & & $\sqrt{ }$ \\
\hline
\end{tabular}


Formas de organização da demanda de firmas de TI no mercado de trabalho

\begin{tabular}{|c|c|c|c|c|c|}
\hline & $\begin{array}{l}\text { Plano de Cargos e } \\
\text { Salários }\end{array}$ & $\sqrt{ }$ & & & $\sqrt{ }$ \\
\hline & $\begin{array}{l}\text { Sistema Informático de } \\
\text { Gestão de RH }\end{array}$ & $\sqrt{ }$ & $\sqrt{ }$ & $\sqrt{ }$ & $\sqrt{ }$ \\
\hline & $\begin{array}{ll}\text { Pesquisa } & \text { Radar } \\
\text { Tecnológico } & \end{array}$ & $\sqrt{ }$ & & & \\
\hline & $\begin{array}{l}\text { Reunião de Decisão de } \\
\text { Contratação }\end{array}$ & & & & $\sqrt{ }$ \\
\hline & $\begin{array}{l}\text { Teste de Exercício } \\
\text { Técnico }\end{array}$ & & & $\sqrt{ }$ & \\
\hline & Testes Lógicos & & & $\sqrt{ }$ & \\
\hline & $\begin{array}{l}\text { Entrevista } \\
\text { Técnica/Profissional }\end{array}$ & & & $\sqrt{ }$ & \\
\hline & $\begin{array}{l}\text { Entrevista } \\
\text { Comportamental }\end{array}$ & & & $\sqrt{ }$ & \\
\hline & Entrevista de Valores & & & $\sqrt{ }$ & \\
\hline & Cultura da Empresa & & & $\sqrt{ }$ & \\
\hline & $\begin{array}{ll}\text { Programas } & \text { de } \\
\text { Recomendação } & \end{array}$ & & $\sqrt{ }$ & & \\
\hline & Site da Empresa & & $\sqrt{ }$ & & \\
\hline & $\begin{array}{l}\text { Formulários } \quad \mathrm{de} \\
\text { Assessment }\end{array}$ & & & $\sqrt{ }$ & $\sqrt{ }$ \\
\hline & Currículos & & $\sqrt{ }$ & $\sqrt{ }$ & \\
\hline & Banco de Currículos & & $\sqrt{ }$ & $\sqrt{ }$ & \\
\hline & $\begin{array}{lrl}\text { Sites de } & \text { Redes } \\
\text { Profissionais } & \end{array}$ & & $\sqrt{ }$ & & \\
\hline & Sites de Redes Sociais & & $\sqrt{ }$ & & \\
\hline & $\begin{array}{ll}\text { Eventos } & \text { em } \\
\text { Comunidades de TI }\end{array}$ & & $\sqrt{ }$ & & \\
\hline & Universidades & & $\sqrt{ }$ & & \\
\hline & $\begin{array}{l}\text { Sites de Vagas } \\
\text { Emprego }\end{array}$ & & $\sqrt{ }$ & & \\
\hline Total & 30 & 10 & 13 & 16 & 10 \\
\hline
\end{tabular}

Através da análise dos dados, identificamos que a capacidade de cálculo das empresas é exercida em quatro operações. Este achado difere da definição de Michel Callon (1998; 2004) do cálculo econômico como composto de três operações, não contemplando a operação que 
NORUS - v4, n.5, jan - jul 2016.

denominamos de "planejamento da demanda". Compreendemos que, nessa última, a firma define a sua demanda, isto é, o que ela valoriza ao contratar um trabalhador. O planejamento da demanda envolve, portanto, a definição de perfis de trabalhador valorizados pela firma em termos de competências técnicas e comportamentais. Nesse momento, articulando principalmente agentes humanos ao nível da gestão da empresa e dispositivos de cálculo que informam sobre o mercado de trabalho (pesquisa salarial, por exemplo), mobilizam-se relações sociotécnicas que estabelecem os perfis de trabalhadores a serem demandados no mercado de trabalho. Esse planejamento da demanda é feito através de relações sociotécnicas (conforme quadros 3 a 6) que constroem uma relação entre a demanda da firma por força-de-trabalho e as suas necessidades relativas ao seu processo produtivo, tornando este último capaz de encaminhar as estratégias comerciais da empresa que visam atender ao nível de demanda no mercado de produtos. Constatamos essas relações sociotécnicas e essa operação através das entrevistas com os diretores de RH, que estão diretamente envolvidos nesta operação através da relação com os membros da direção comercial, executiva e técnica. Após o planejamento da demanda, a firma executa as outras operações de cálculo: recrutamento (classificar), seleção (julgar) e contratação (planejar).

Nas relações sociotécnicas que estruturam a operação de recrutamento, a firma verifica a disponibilidade no mercado de trabalho dos perfis valorizados de profissionais. Nessa operação de cálculo, as relações sociotécnicas entre agentes humanos (principalmente os situados no setor de RH) e dispositivos de cálculos (ver quadros 3 a 6) possibilitam à firma estabelecer uma avaliação da oferta no mercado de trabalho conforme os perfis de trabalhadores por ela demandados. Dispositivos de cálculo como site da empresa, redes sociais virtuais, programas de recomendações e eventos e contatos com Universidades, estabelecem as condições de possibilidade para que a firma calcule a disponibilidade e qualidade da oferta que lhe interessa no mercado de trabalho; sendo que esse cálculo é feito através da representação dessa oferta na forma de um dispositivo de cálculo, a saber, o banco de currículos da empresa. Através das entrevistas com as recrutadoras constatamos, então, que a oferta de força de trabalho é construída na forma de um banco de currículos através das relações sociotécnicas entre agentes humanos e não-humanos, mobilizados na operação de recrutamento. Em termos mais simples, a oferta de força de trabalho se torna calculável para fïrma na medida em que ela constrói um banco de currículos que depende das condições de possibilidade da sua rede sociotécnica, por exemplo, as recrutadoras relataram que os programas de recomendação (dispositivo de cálculo) era um dos principais canais de recrutamento, seguindo pelas candidaturas através do site da empresa. Na EC4, em contraste, o principal meio de recrutamento eram os eventos organizados pela empresa junto com as "comunidades de TI" em diferentes regiões 


\section{Formas de organização da demanda de firmas de TI no mercado de trabalho}

do Brasil. Portanto, as entrevistas com as recrutadoras mostraram que a oferta de força de trabalho se torna calculável através desses dispositivos de recrutamento acionados que, por sua vez, cumprem a função de compor o banco de currículo. Este último é o dispositivo de cálculo encarregado de estabelecer uma representação calculável da oferta no mercado de trabalho para as recrutadoras.

Na operação de seleção, a empresa julga as ofertas disponíveis no mercado de trabalho em função dos perfis valorizados que constituem a sua demanda. As relações sociotécnicas entre agentes humanos (funcionários do $\mathrm{RH}$ e da parte técnica da empresa) e dispositivos de cálculo (testes técnicos e psicológicos, técnicas de entrevistas e formulários de avaliação dos candidatos, entre outros) buscam calcular o perfil de competências dos candidatos tanto na dimensão técnicoprofissional como na comportamental ${ }^{6}$. A definição dessas competências é dada aos agentes humanos através de dispositivos de cálculo divididos em dois grupos: 1) os pertencentes à firma que consistem nas definições da cultura da empresa (mais diretamente relacionada às competências comportamentais) e no plano de cargos e funções (competências profissionais e técnicas); 2) os pertencentes aos profissionais da área técnica, especialmente os gestores dessas áreas, que são os conhecimentos tácitos que advêm da formação e experiência profissional desses profissionais. As relações sociotécnicas formadas por agentes humanos e dispositivos de cálculo (vide quadros de 3 a 6), na operação de seleção, estruturam as condições para firma calcular a oferta disponível no mercado de trabalho em termos de um julgamento sobre o quanto essa oferta atende a sua demanda, isto é, se os trabalhadores ofertantes no mercado de trabalho possuem competências técnicas, profissionais e comportamentais em consonância com aquelas dos perfis de profissionais valorizados e demandados pela firma.

Por último, ela planeja e decide pela contratação de um ou mais dos ofertantes identificados e selecionados no mercado de trabalho. Os agentes humanos e dispositivos que entram em relação sociotécnica nessa operação de cálculo (conforme os quadros de 3 a 6), planejam quem dos candidatos irão contratar e para qual cargo e salário. A decisão de contratação de um candidato representa, então, um planejamento feito pela firma sobre quais procedimentos ela precisa executar (quem irá contratar? qual salário e benefícios precisam pagar? qual função da empresa o contratado irá exercer?) para realizar a demanda que a motivou adentrar o mercado de trabalho.

Tal como dissertamos na introdução deste artigo, as firmas mais próximas ao modelo organizacional da nova economia apresentam maior variedade de agentes humanos e de dispositivos

\footnotetext{
${ }^{6}$ No caso da EC4, há ainda uma entrevista que verifica uma dimensão dos valores morais do candidato. Isso acontece porque a empresa se define como uma organização comprometida com os valores de justiça social; assim, os candidatos também devem comungar desses valores.
} 
NORUS - v4, n.5, jan - jul 2016.

de cálculos, assim como maior adensamento das relações sociotécnicas entre esses agentes para executarem as operações de cálculo descritas acima. Nesse sentido, cabe relembrar que o caso que mais se aproxima das características organizacionais típicas da nova economia é o EC4 (total de agentes e dispositivos na rede é de 30). Em posição intermediária podem ser classificados em ordem de maior para menor proximidade, respectivamente, o EC2 (total de 28) e o EC3 (total de 23). Por fim, o caso que mais distancia da nova economia em termos dessas características organizacionais é o da EC1 (total de 13).

Por fim, constatamos que a EC4, além do maior número, também apresentou um modelo mais adensado, ou seja, em cada uma das quatro operações do cálculo econômico, a EC4 possui um número maior de agentes humanos e dispositivos do que as outras empresas estudadas. Emblemático desse aspecto é o fato da EC4 adotar um modelo no qual cada contratação de um candidato deve ocorrer por decisão unânime em reunião com todos os envolvidos no processo de seleção do candidato (no mínimo 10 pessoas); enquanto que, nos demais casos, a decisão de contratação é feita pelo gestor da área técnica que entrevistou os candidatos e, então, ao RH cabe os tramites burocráticos necessários para contratação do(s) selecionado(s).

\section{CONSIDERAÇÕES FINAIS}

Muito mais do que descrever em termos conceituais processos empíricos, a análise que empreendemos aqui sobre o cálculo da firma no mercado de trabalho, permite constatar que a realização da demanda é antes de tudo um fenômeno organizacional particular e socialmente construído. O que ocorre não é simplesmente um cálculo motivado por preferências estáveis, informado pelo sistema de preços e levado a cabo por um agente socialmente atomizado. A firma como demandante está enraizada em um conjunto de relações sociotécnicas que são formadas e cessadas conforme cada operação que compõe o seu cálculo econômico no mercado de trabalho.

Ademais, somente através desse tipo de análise é possível compreender a relação entre as modalidades de cálculo (definidas em termos das redes sociotécnicas formadas em cada uma das quatro operações que o conformam) e o contexto organizacional da nova economia. Em outras palavras, o cálculo econômico, em razão dessa perspectiva de análise, passa a ser compreendido não mais em abstrato, mas como modalidade de ação situada no contexto social e econômico mais amplo. Nesse sentido, evidenciamos que à medida que a firma apresenta uma maior proximidade com as características organizacionais da nova economia, mais a sua rede sociotécnica aumenta de volume e de densidade. 


\section{Formas de organização da demanda de firmas de TI no mercado de trabalho}

Todavia, essas diferenças nas redes sociotécnicas não podem ser atribuídas exclusivamente à aproximação dos modelos organizacionais das empresas em relação à nova economia; a análise dos dados revelou que também influem aspectos organizacionais particulares de cada empresa, por exemplo, na EC1 e na EC3 identificou-se que o status ainda em formação dos seus setores de RH, limitava a inserção de dispositivos de cálculo como programas de recomendação, cultura da empresa e planos de cargos e salários. Nesse sentido, os casos da EC2 e da EC4 apontam para a influência do fato da empresa ser uma multinacional ou não, pois esses dois casos apresentaram modelos bem estruturados de procedimentos de planejamento da demanda, recrutamento, seleção e contrato de novos trabalhadores. Talvez porque essas duas empresas serem multinacionais, isso imponha à direção corporativa maiores exigências em padronizar as suas práticas de recursos humanos.

Todavia, essas conclusões alcançadas precisam ser consideradas através dos possíveis vieses em função dos limites na coleta de dados e na escolha dos estudos de casos desta pesquisa. No que concerne à seleção dos casos, cabe destacar que estes representam uma pequena parte do universo de empresas de TI, que possui um grande número de micro e pequenas empresas, ou seja, com características organizacionais diferentes dos casos estudados. $\mathrm{Na}$ coleta de dados configuram-se dois principais limitadores ao estudo: primeiro, tivemos acesso maior para entrevistas com os gestores de RH e recrutadores; segundo, as quatro empresas concederam níveis diferentes de acesso para fazer entrevistas.

Tendo em vista esses limites na coleta de dados entre as empresas, alguns vieses podem ser cogitados. O primeiro deles advém do maior número de entrevistas com pessoas do $\mathrm{RH}$, o que pode ter estruturado uma visão unidimensional das firmas; isto é, não se obteve acesso à visão da organização e de estratégias da empresa através do ponto de vistas de gestores de áreas como a financeira, a comercial ou mesmo por parte de diretores gerais ou executivos. Em segundo lugar, não sendo possível observar na prática os processos de recrutamento e seleção, esta pesquisa está se respaldando apenas nas percepções e conhecimentos de algumas das pessoas encarregadas dessas práticas, conhecimentos e percepções provocados e formulados a partir das condições particulares de entrevistas semiestruturadas (POUPART, 2008). Em terceiro lugar, o acesso restrito ou a não autorização de entrevistas com profissionais técnicos que participam da seleção de candidatos a vagas de emprego na firma, pode ter conduzido a uma percepção acerca das qualificações e do perfil de funcionários demandados pela firma, restrita ao que pensam os profissionais de RH encarregados de avaliar no processo de seleção. Finalmente, em quarto lugar, o fato de não se ter conseguido uniformidade no grau de acesso, que deveria estar expresso no mesmo número de 
NORUS - v4, n.5, jan - jul 2016.

entrevistas e na variabilidade de tipos de entrevistados, faz correr o risco de que as conclusões alcançadas que dizem respeito a diferenças entre as firmas resultem de diferenças nessa variabilidade de acesso aos dados.

Por fim, cabe destacar o papel relevante que as tecnologias de informação assumem como dispositivos de cálculo. Se as redes se adensam e se tornam mais volumosa como resposta a uma maior aproximação do modelo organizacional típico da nova economia, ao seu turno, esse processo exige da firma maior poder em coletar e processar informações; as tecnologias de informação justamente atuam sobre essa capacidade de coletar e processar informações. Nesse sentido, os estudos de caso revelaram que os sistemas informáticos de gestão de RH são vitais para o bom desempenho dessa capacidade, isto é, esses dispositivos de cálculo se revelaram fundamentais em coordenar as relações sociotécnicas entre agentes humanos e dispositivos na execução das operações de cálculo econômico da firma no mercado de trabalho. Assim sendo, este artigo chama a atenção para se abrir uma linha de pesquisa ainda pouco explorada pela análise sociológica dos mercados de trabalho, a saber, o papel da agência não-humana no funcionamento e mudanças nesses mercados. Nesta pesquisa identificamos uma série desses dispositivos de cálculo, por exemplo, os sistemas informáticos de RH, os sites de vagas de emprego, formatações de currículos, planos de cargos, salários e carreiras, entre outros. Encerramos, então, por cogitar se estamos presenciando a tendência da ampliação do número e influência desses e outros agentes nãohumanos no mercado de trabalho, em razão dos processos de mudanças relacionados à nova economia. Deixamos em aberto para futuros estudos explorar as implicações dessa possibilidade.

\section{REFERÊNCIAS BIBLIOGRÁFICAS}

BARDIN, L. Análise de Conteúdo. Lisboa: Edições 70, 1979.

BELL, D. O Advento da Sociedade Pós-Industrial. São Paulo: Cultirx, 1973.

CALLON, M. Introduction: the embeddedness of economic markets in economics. In: (Ed).

The Laws of the Markets. Oxford: Blackwell Publishers, 1998. . Actor-network theory - the market test. In: LAW, J; HASSARD, J. (Ed). Actor-Network Theory and After. Oxford: Blackwell, 2004. p. 181-95.

. An Essay on the Growing Contribution of Economic Markets to the Proliferation of the Social. Theory, Culture \& Society, v. 24, n. Jul./Ago., p. 139-163, 2007. 
Formas de organização da demanda de firmas de TI no mercado de trabalho

. Entrevista com Michel Callon: Dos estudos de laboratório aos estudos coletivos

heterogêneos, passando pelos gerenciamentos econômicos. Sociologias, v. 10, n. 19, p. 302-321, 2008.

CALLON, M.; MÉADEL, C.; RABEHARISOA, V. The economy of qualities. Economy and Society, v. 31, n. 2, p. 194-217, 2002.

CALLON, M.; MUNIESA, F. Economic Markets as Calculative Collective Devices. Organization Studies, v. 26, n. 8, p. 1229-1250, 2005.

CASTELLS, M. Materials for an exploratory theory of the network society. British Journal of Sociology, v. 51, n. 1, p. 5-24, 2000.

A Sociedade em Rede. 10. ed. São Paulo: Editora Paz e Terra, 2007. Volume 1.

DOGANOVA, L.; EYQUEM-RENAULT, M. What do business models do? Innovation devices in technology entrepreneurship. Research Policy, v. 38, n. 10, p. 1559-1570, 2009.

FERNANDEZ, R. M; CASTILLA, E. J; MOORE, P. Social Capital at Work: Networks and employment at a Phone Center. American Journal of Sociology, v. 105, n. 5, p. 1288-1356, 2000.

FERNANDEZ, R. M.; SOSA, M. L. Gendering the Job: networks and recruitment at a Call Center. American Journal of Sociology, v. 111, n. 3, p. 859-904, 2005.

FLIGSTEIN, N; DAUTER, L. The Sociology of Markets. Annual Review of Sociology, v. 33, p. 105-28, 2007.

GERRING, J. Case Study Research: principles and practices. New York: Cambridge University Press, 2007.

GIDDENS, A. As Consequências da Modernidade. São Paulo: Editora da UNESP, 1991.

GUIMARÃES, S. M. K. Apresentação: Trabalho, emprego e relações laborais em setores intensivos em conhecimento. In: (Org.). Trabalho, Emprego e Relações Laborais em Setores

Intensivos em Conhecimento: Brasil, México e Canadá. Porto Alegre: Editora da UFRGS, 2009. p. 7-20.

HARDIE, I; MACKENZIE, D. Assembling an economic actor: the agencement of a Hedge Fund. The Sociological Review, v. 55, n. 1, p. 57-80, 2007.

HARVEY, D. A Condição Pós-Moderna: uma pesquisa sobre as origens da mudança cultural. 6. ed. São Paulo: Loyola, 1996.

JAMESON, F. Pós-Modernidade e Sociedade de Consumo. Revista Novos Estudos CEBRAP, n. 12, p. 16-26, 1985.

KUMAR, K. Da Sociedade Pós-Industrial à Pós-Moderna: Novas teorias sobre o mundo contemporâneo. Rio de Janeiro: Jorge Zahar, 1997.

LATOUR, B. On Recalling ANT. The Sociological Review, v. 46, p. 15-25, 1999. 
NORUS - v4, n.5, jan - jul 2016.

Reassembling the Social: An Introduction to Actor-Network-Theory. New York: Oxford University Press, 2006.

LAW, J. After ANT: complexity, naming and topology. The Sociological Review, v. 46, p. 1-14, 1999.

MARCHAL, E. ; RIEUCAU, G. Le recrutement. Paris: La Découverte, 2010.

MARSDEN, P. V. Selection Methods in US Establishments. Acta Sociologica, v. 37, p. 287-301, 1994.

MASUDA, Y. A Sociedade da Informação como Sociedade Pós-Industrial. Rio de Janeiro: Ed. Rio, 1982.

MERLE, I. Le recrutement des opérateurs dans une usine chimique à haut risque : le paradoxe du charcutier. Sociologie du Travail, v. 54, n. 4, p. 475-494, 2012.

MUNIESA, F; MILLO, Y; CALLON, M. An introduction to market devices. The Sociological Review, v. 55, Special Issue 2, p. 1-12, 2007.

PEREIRA, R. M.; OLIVEIRA, S. R. de. Taylorismo e fordismo: A racionalidade técnica na organização. In: PICCININI, V. C.; ALMEIDA, M. L. de; OLIVEIRA, S. R. de (Org.). Sociologia e Administração: Relações sociais nas organizações. Rio de Janeiro: Elsevier, 2011. p. 239-256.

PORTES, A. Economic Sociology: A systematic inquiry. Princeton: Princeton University Press, 2010.

POUPART, J. A entrevista de tipo qualitativo: considerações epistemológicas, teóricas e metodológicas. In: POUPART, J. et. al. (Org.). A Pesquisa Qualitativa: enfoques epistemológicos e metodológicos. Petrópolis: Vozes, 2008. p. 215-253.

POWELL, W. W; SNELlMAN, K. The Knowledge Economy. Annual Review of Sociology, v. 30, p. 199-220, 2004.

RIVERA, L. A. Hiring as Cultural Matching: The Case of Elite Professional Service Firms. American Sociological Review, v. 77, n. 6, p. 999-1022, 2012.

ROBERTS, J. M. Poststructuralism against poststructuralism: Actor-network theory, organizations and economic markets. European Journal of Social Theory, v. 15, n. 1, p. 35-53, 2012.

ROSCOE, P. Economic embeddedness and materiality in a financial market setting. The Sociological Review, v. 61, p. 41-68, 2013.

RUBINEAU, B; FERNANDEZ, R. M. Missing Links: Referrer Behavior and Job Segregation. Management Science, v. 59, n. 11, p. 2470-2489, 2013.

SAYES, E. Actor-Network Theory and methodology: Just what does it mean to say that nonhumans have agency? Social Studies of Science, v. 44, n. 1, p. 134-149, 2013.

SMELSER, N. J; SWEDBERG, R. Introducing Economic Sociology. In: (Ed). The Handbook of Economic Sociology. $2^{a}$ Ed. Princeton: Princeton University Press, 2005. p. 3-25. 
Formas de organização da demanda de firmas de TI no mercado de trabalho

STEINER, P. A Sociologia Econômica. São Paulo: Atlas, 2006. 